\title{
Reducing Warp and Checking in 4 by 4 Beams from Small-Diameter Tropical Species (Tectona grandis, Gmelina arborea, and Cordia alliodora) Obtained by Turning the Pith Inside Out
}

\author{
Rafael Serrano Montero \\ Róger Moya
}

\begin{abstract}
Small-diameter logs from plantation trees are prone to warp and to produce checks due to the presence of juvenile wood, growth stresses, and asymmetric shrinkage during the drying process. In the present study, we analyzed the possibility of producing sawn timber beams by using the inside-out (ISO) process. The material for the sawn timber beams was obtained from small-diameter logs of three tropical species planted in Costa Rica (Gmelina arborea, Tectona grandis, and Cordia alliodora). Changes in warp (crook and twist), checks (quantity, length, and depth), flexural and shear resistance, and glue line delamination were evaluated. We found that it was possible to produce beams from small-diameter logs of fast-growing plantations. This was achieved by turning the pith inside out and then gluing the green pieces. The ISO beams showed less warp and checking compared with solid wood. The modulus of rupture in the flexural test was not affected; however, the modulus of elasticity decreased. In the case of the glue line's shear resistance, the performance of G. arborea and $C$. alliodora were similar to that of solid wood, but $T$. grandis presented adherence problems, which caused low values of shear resistance.
\end{abstract}

\footnotetext{
A

great variety of reforestation species (e.g., Tectona grandis, Cupressuss lusitanica, Acacia mangium, and Gmelina arborea) have been introduced to Costa Rica, mainly for timber production (Moya et al. 2013). Fastgrowing native species (rotation periods of less than $20 \mathrm{y}$ ), such as Cordia alliodora, Terminalia amazonia, Terminalia oblonga, Vochysia guatemalensis, Bombacopsis quinata, Alnus acuminata, and Swietenia macrophylla, have also been used for timber production (Serrano and Moya 2011). These species have been widely used in forest plantations both because of their wood quality and because of their rapid growth (Serrano and Moya 2011).

The practice of thinning is common in fast-growing plantations. Trees removed during thinning have smaller diameters and contain a high proportion of juvenile wood. This produces high growth stresses and warp in the lumber (Patterson and Xie 1998). During the first 10 years of growth, juvenile wood appears around the pith and along the bole of the tree (Darmawan et al. 2013).

The most remarkable defects (warp, checks, splits, growth stresses, and contractions) regarding dimensional performance of juvenile wood occur during the drying
}

process (Ratnasingam et al. 2013). For example, the relief of tensile stresses in the outer rings and compression near the pith when cutting a piece close to the pith can cause outward edge curving. During the drying process, the section near the pith shrinks more longitudinally than the area farther from the pith (Serrano and Cassens 2001). As a result, the lumber tends to straighten when drying (Serrano and Cassens 2001). The success of the inside-out (ISO) process is owing to the fact that drying stresses counterbalance the growth stresses that are relieved during sawing.

The ISO process is based on the production of a central block, usually 10 by $10 \mathrm{~cm}$ (Figs. 1a and $1 \mathrm{~b}$ ). The block is cut into two subblocks measuring 5 by $10 \mathrm{~cm}$, with the

The authors are, respectively, Researcher and Professor and Researcher, Escuela de Ingeniería Forestal, Instituto Tecnológico de Costa Rica, Cartago, Costa Rica (rserrano2@gmail.com,rmoya@, itcr.ac.cr [corresponding author]). This paper was received for publication in September 2014. Article no. 14-00089.

(C) Forest Products Society 2015.

Forest Prod. J. 65(5/6):285-291.

doi:10.13073/FPJ-D-14-00089 


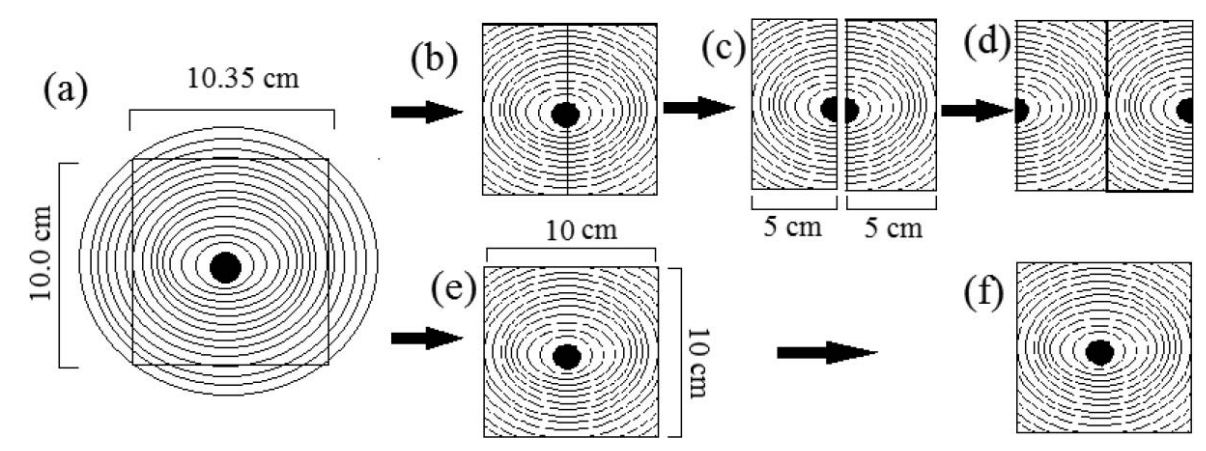

Figure 1.-Sawing pattern used in the logs and lumber samples obtained: (a) central block, ( $b$ and $c$ ) sawing pattern for moving the pith out (inside-out [ISO] beams), (d) glued exterior surfaces, and (e and f) normal sawing pattern (control beams).

sides parallel to the pith (Fig. 1c). Then, the sides of the cants are smoothed with a moulder. Next, the exterior surfaces are glued with waterproof adhesive (Fig. 1d), and it is turned ISO and clamped together. The new beams (called ISO beams) are kiln-dried and moulded to final size (Patterson et al. 2002). In addition to reducing warp, the ISO beams reduce checking because the radial faces, which are now exposed, shrink less than the tangential faces, thus reducing the tendency to check (Forest Products Laboratory 1987).

Issues associated with the processing of logs that come from thinning have been noted previously. For example, Patterson et al. (2002) evaluated the economic feasibility of using small-diameter logs to produce structural beams. Those authors concluded that the constraining variables in determining feasibility were the production level and the discount rate. Scholl et al. (2008) discussed the implications of wood from small-diameter logs on drying process and wood quality. Espinoza and Moya (2013) evaluated the yield of small-dimension logs in tropical species. Those authors found that the recovery of lumber varied from 30 to 50 percent. Also, Moya et al. (2013) found twist, split, and check in a high percentage of the sawn wood from 10 species growing in tropical climates.

Increased handling costs, lower average lumber grades, and drying-induced defects are potential problems associated with the processing of small-diameter logs into lumber (Scholl et al. 2008). Several studies have examined alternative processing methods that might be used to process small-diameter logs in an economic way (Maeglin and Boone 1988, Hamner et al. 2006). Serrano and Cassens (2001) as well as Patterson et al. (2002) studied the production of ISO beams from small-diameter logs.

Few studies, however, have been done with smalldiameter tropical species, in which warp is common. In Costa Rica's sawmills, a need exists for techniques to increase wood quality. The objective of the present study was to evaluate the production and subsequent drying of ISO beams from small-diameter logs of three main species planted in Costa Rica: G. arborea, T. grandis, and $C$. alliodora. The evaluation considered the presence of defects (crook, twist, and check quantity, length, and depth), the mechanical flexural strength, and the shear strength. The results will help improve the value of small-diameter logs and increase the productivity of thinning processes in fastgrowing plantations.

\section{Materials and Methods}

\section{Raw material}

The material used in the present study was obtained from the thinning of three commercial reforestation species used in Costa Rica: G. arborea (beechwood), T. grandis (teak), and $C$. alliodora (laurel). Information about each species is described in Table 1.

\section{Tree selection and log sampling}

Twenty trees were selected for each species. The selected trees had diameters close to the plantation's average diameter at breast height, which varied from 18 to $28 \mathrm{~cm}$. Central blocks measuring 10 by $10 \mathrm{~cm}$ were produced. Two $2.5-\mathrm{m}$-long logs were cut from each sample tree. The first $\log$ was cut from the tree base up to $2.5 \mathrm{~m}$, and the second $\log$ was cut between 2.5 and $5 \mathrm{~m}$.

\section{Sawing pattern}

The 40 sampled logs for each species were cut using a scrag saw. Each log was sawn to obtain a 10.35 by $10-\mathrm{cm}$ block with the same length as the log, equivalent to $2.5 \mathrm{~m}$ (Fig. 1a). After obtaining these 40 central blocks, the blocks were randomly divided in two lots $(n=26$ and $n=14)$. The 26 blocks of the first lot were cut through the pith zone using a straight-line rip saw with 3.5 -mm cutting thickness (Figs. $1 \mathrm{~b}$ and $1 \mathrm{c})$. This cutting pattern was called "ISO process" (moving the pith out or ISO; Fig. 1d). In this manner, two 5 by $10-\mathrm{cm}$ pieces were obtained from each block; these pieces were then wrapped in plastic to prevent drying. For the 14 blocks in the second lot, the dimensions were set at 10 by $10 \mathrm{~cm}$ (Fig. 1e), and the blocks were wrapped in plastic to prevent drying.

\section{Turning the pith ISO}

Three types of treatments were applied. The first treatment consisted in leaving the fourteen 10 by $10-\mathrm{cm}$ blocks as a control group (Figs. 1e and 1f). The second and third treatments (ISO-1 and ISO-2, respectively) were applied to the two pieces obtained from the separation of the pith. In the ISO-1 and ISO-2 treatments, the pieces were glued on the tangential face of the outermost part of the blocks that were cut in the direction of the pith (Figs. 1b through 1d). The ISO-1 treatment used Resistol 5003 (HB Fuller) and the ISO-2 treatment Reactive 8000 (Franklin International) to glue the two pieces (Figs. $1 \mathrm{~b}$ through $1 \mathrm{~d}$ ). In these last two treatments, the two pieces were then joined 
Table 1.-Basic information for each species used in the experiments.

\begin{tabular}{llll}
\hline \hline & \multicolumn{1}{c}{ Gmelina arborea } & \multicolumn{1}{c}{ Tectona grandis } & \multicolumn{1}{c}{ Cordia alliodora } \\
\hline Location & Cariari, Guápiles, and Limón & Aguas Zarcas, San Carlos, and Alajuela & Saino, Pital, San Carlos, and Alajuela \\
Age (y) & 7 & 8 & 13 \\
Initial spacing (m) & $3 \times 3$ & $2.4 \times 2.4$ & $2.5 \times 2.5$ \\
Material for propagation & Clone $\times$ A94 & Stumps and bags & Nursery \\
Density (trees/ha) at sampling time & 322 & 754 & 700 \\
Avg. DBH $(\mathrm{cm})^{\mathrm{a}}$ & 28.10 & 16.50 & 18 \\
Total height $(\mathrm{m})$ & $12.65^{\mathrm{b}}$ & 16.60 & 18 \\
\hline \hline
\end{tabular}

${ }^{\mathrm{a}} \mathrm{DBH}=$ diameter at breast height.

${ }^{\mathrm{b}}$ Only the commercial height was measured for this species.

at the tangential faces, leaving the radial faces of the pith zone in the outer part of the block and the two tangential faces (external zone of the block or near the bark) in the inner part of the glued piece (Fig. 1d). All gluing was done with wood in the green condition.

\section{Adhesives used and gluing process}

The two types of adhesives used are intended for wood with moisture content above the fiber saturation point (i.e., higher than 30\%). The Resistol 5003 adhesive (LAMHB glue) used in ISO-1 consists of one-component, resin-based polyurethane adhesive. For ISO-2, the resin in Reactive 8000 (LAMFK glue) is also a polyurethane component. Curing in both adhesives was aided by the moisture contained in the environment as well as in the wood. The open assembly time of both adhesives was between 20 and 30 minutes. Pressure applied to the pieces of glued wood was $12 \mathrm{~kg} / \mathrm{cm}^{2}$ for a period of 2 hours. A flat-plate, plywood production press (Model PL/9/SCF; ItalPress) was used. The time and pressure of the press were controlled.

\section{Drying}

Both treated beams and control beams $(10$ by $10 \mathrm{~cm})$ were subjected to a conventional chamber drying process after the adhesive was applied and curing was achieved. The objective of drying was to achieve a final moisture content of 15 percent. Drying was conducted using an electrically heated, 2- $\mathrm{m}^{3}$-capacity NARDI drying kiln. The drying schedules for each species were as follows: The " $\mathrm{H}$ " schedule proposed by Sidney et al. (1988) was used for $T$. grandis, the schedule proposed by Muñoz and Moya (2008) was applied to $G$. arborea, and the T6-D2 schedule proposed by Sidney et al. (1988) was used for C. alliodora .

\section{Measurement of warp and check defects}

Defects such as crook, twist, and checks were measured in both glued and control beams after the drying process was concluded. Checks were evaluated in terms of the number of checks found in the piece, the length of the longest check, and the maximum check depth. This procedure has been detailed previously by Moya et al. (2013) and by Salas and Moya (2014).

\section{Tests on flexural strength}

Thirty-four flexure tests were conducted on each species, including the 14 beams in the control treatment and the 20 beams obtained after the pith separation. From the latter 20 beams, 10 corresponded to ISO-1 (LAMHB glue) and 10 to ISO-2 (LAMFK glue). The ASTM Standard D198 (ASTM
International 2013a) was used, and a two-point load was applied in the static flexure test. In this test, the modulus of rupture (MOR) and the modulus of elasticity (MOE) were calculated.

\section{Measurement of the moisture content, shear resistance, and failure in glue line}

Three glued beams were used per adhesive type in order to determine the moisture content, shear resistance, and failure in the glue line. Three samples were extracted from each beam ( $n=9$ samples per treatment) to measure the parameters mentioned above. The moisture content was evaluated by leaving the sample in an oven for 24 hours at a temperature of $103^{\circ} \mathrm{C} \pm 1{ }^{\circ} \mathrm{C}$. The sample's weight was measured before and after the drying process, and moisture content was calculated according to ASTM D143 (ASTM International 2013b). The shear strength or shear stress at the glue line was calculated according to ASTM D905-08 (ASTM International 2013c). The evaluation of the failure in the glue line of the beams was performed by means of a soaking-drying cycle. In this test, three glued pieces were obtained per adhesive type (ISO-1 and ISO-2) by the use of Method B from ASTM D1101-97a (ASTM International 2013d). The variable measured in the failure test was the glue line's length opening as a percentage from the glue line's total length. The test was conducted on the beam's transverse face.

\section{Statistical analysis}

The assumptions of normal distribution, homogeneity variance, and absence of general extreme data were verified using the PROC UNIVARIATE procedure of SAS Version 8.1 for Windows (SAS Institute Inc.). The beams' parameters (warping [crook and twist], check dimensions, MOR and MOE in the flexural test, stress resistance in the shear test, and percentage of delamination in the glue line) were compared using analysis of variance (ANOVA), in which the dependent variables were the beams' parameters and the independent variables were the ISO gluing treatments. One-way ANOVA from the SAS software was applied to estimate the significance of the sources of variation. The differences among the average of the beams' parameters were evaluated with a Tukey test.

\section{Results and Discussion Warp and checks}

C. alliodora's quality evaluation showed that crook and depth in checks decreased significantly after the pith separation compared with the control beams. Also, crook 
and depth in checks decreased after gluing the two faces with the adhesives LAMHB (ISO-1) and LAMFK (ISO-2) compared with the control beams (Table 2). For G. arborea, the ISO-1 beams obtained a significant reduction in crook and in the number, length, and depth of checks compared with the control beams; the ISO-2 beams also showed a reduction of crook and depth of checks. For T. grandis, the ISO beams showed a significant reduction of crook and the depth of checks; however, the length of checks increased (Table 2). Regarding the defect twist, no significant differences were found among the treatments for each species.

The reduction in defects (especially crook and length and depth of checks) increased the beams' overall quality. In control beams, the relief of growth stresses occurred during the sawing process, which caused the beams to warp (Serrano and Cassens 2001). The ISO beams showed torsions due to the initial sawing process (Fig. 1a), pith separation (Fig. 1c), and the gluing process (Fig. 1d). The growth and the drying stresses that act against each other reduced the strains. The strain reduction produced fewer checks in the beams and a reduction of crook and check length and depth of the beams (Patterson and Xie 1998). These results are congruent with the ones from Patterson and Xie (1998), which established that ISO beams had the same mechanical resistance as normal beams. However, those authors used ISO beams from a four-part division with gluing later in the process instead of dividing the ISO beams in half, as was done in the present study (Fig. 1).

The present study showed that for the three species examined, warp (crook and twist mainly) and checks were reduced. Furthermore, the pith separation reduced the growth stresses. The two types of adhesives tested also helped in the reduction of defects like checks. No statistical difference was found between the two types of adhesive used.

\section{Flexural test}

The evaluation of MOR and MOE in the flexural test determined that in $C$. alliodora, the MOR for ISO-2 beams was statistically higher than the MOR obtained from the ISO-1 beams and from the control beams (Fig. 2a). In the ISO-1 and ISO-2 C. alliodora beams, the MOE was statistically lower than that obtained from the control beams (Fig. 2b). No significant differences were observed in the MOR among the treatments that were applied to G. arborea and T. grandis (Figs. 2c and 2e); however, the MOE was statistically lower than in the control beams (Figs. 2d and 2f).

The ISO beams' MOE reduction for all three evaluated species, and the ISO beams' MOR reduction in $C$. alliodora (Fig. 2a), could be explained by the pith separation. In pith separation, the inner, juvenile wood of the $\log$ is moved to the outer parts of the beam, which are subject to a greater stress during the flexure test (Patterson and Xie 1998). However, the lack of difference between the ISO beams' MOR for G. arborea and T. grandis can be attributed to the low difference between the juvenile and mature woods (Moya and Tomazello 2009, Moya et al. 2014).

\section{Measurement of the moisture content, shear resistance, and failure in the glue line}

Control beams showed a moisture content similar to the ISO beams after the gluing process. In $G$. arborea, the moisture content was close to 100 percent, while in $T$. grandis and $C$. alliodora, moisture content varied from 35.11 to 37.53 percent in $T$. grandis and from 44.12 to 46.31 percent in $C$. alliodora (Table 3).

The dry-condition shear test in C. alliodora's ISO-2 beams proved to be statistically higher than control beams in shear stress values. The gluing process in the ISO-1 beams showed no significant difference compared with the control beams in this parameter. In addition, no differences were observed between the two adhesive types used after the pith separation (Fig. 3a) in value of shear stress. In relation to the failure percentage in shear test, no differences were found between the two adhesive types in C. alliodora (Fig. 3b).

For $G$. arborea, the shear strength for the ISO-2 beams was statistically higher than that of the control beams. No statistical difference was found between the ISO-1 beams and the control beams (Fig. 3c). The failure percentage was not higher than 12 percent for the two adhesive types (Fig. 3d).

Table 2.-Values of warp and check determined for three species glued as part of an inside-out (ISO; moving the pith out) test. ${ }^{\text {a }}$

\begin{tabular}{|c|c|c|c|c|c|c|}
\hline Species & Beam type ${ }^{b}$ & Crook (mm) & Twist (mm) & Check quantity & Length of check $(\mathrm{cm})$ & Depth of check $(\mathrm{cm})$ \\
\hline \multirow[t]{3}{*}{ Cordia alliodora } & ISO-1 & $0.78 \mathrm{~A}$ & $3.44 \mathrm{~A}$ & $8.40 \mathrm{~A}$ & $54.20 \mathrm{~A}$ & $1.78 \mathrm{~A}$ \\
\hline & ISO-2 & $1.38 \mathrm{~A}$ & $3.67 \mathrm{~A}$ & $5.80 \mathrm{~A}$ & $45.30 \mathrm{~A}$ & $1.76 \mathrm{~A}$ \\
\hline & Control & $2.37 \mathrm{~B}$ & $3.53 \mathrm{~A}$ & $9.35 \mathrm{~A}$ & $95.80 \mathrm{~A}$ & $3.35 \mathrm{~B}$ \\
\hline Total & & 1.73 & 3.54 & 8.23 & 72.77 & 2.56 \\
\hline \multirow[t]{3}{*}{ Gmelina arborea } & ISO-1 & $1.11 \mathrm{~A}$ & $1.94 \mathrm{~A}$ & $3.90 \mathrm{~B}$ & $21.90 \mathrm{~B}$ & $1.76 \mathrm{~A}$ \\
\hline & ISO-2 & $0.4 \mathrm{~A}$ & $2.06 \mathrm{~A}$ & $6.00 \mathrm{AB}$ & $51.70 \mathrm{AB}$ & $2.49 \mathrm{~A}$ \\
\hline & Control & $3.25 \mathrm{~B}$ & $2.44 \mathrm{~A}$ & $6.70 \mathrm{~A}$ & $84.01 \mathrm{~A}$ & $4.92 \mathrm{~B}$ \\
\hline Total & & 2.01 & 2.22 & 5.83 & 60.40 & 3.52 \\
\hline \multirow[t]{3}{*}{ Tectona grandis } & ISO-1 & $1.22 \mathrm{~A}$ & $3.64 \mathrm{~A}$ & $4.60 \mathrm{~A}$ & $75.52 \mathrm{~A}$ & $2.12 \mathrm{~A}$ \\
\hline & ISO-2 & $1.36 \mathrm{~A}$ & $3.61 \mathrm{~A}$ & $4.40 \mathrm{~A}$ & $85.80 \mathrm{~A}$ & $2.34 \mathrm{~A}$ \\
\hline & Control & $2.38 \mathrm{~B}$ & $3.64 \mathrm{~A}$ & $6.50 \mathrm{~A}$ & $39.78 \mathrm{~B}$ & $4.33 \mathrm{~B}$ \\
\hline Total & & 1.83 & 3.63 & 5.50 & 60.22 & 3.28 \\
\hline
\end{tabular}

a Different letters indicate that the values are statistically different at a confidence level of 95 percent for the same defects.

b The ISO-1 treatment used Resistol 5003 and the ISO-2 treatment Reactive 8000 to glue the two pieces. 

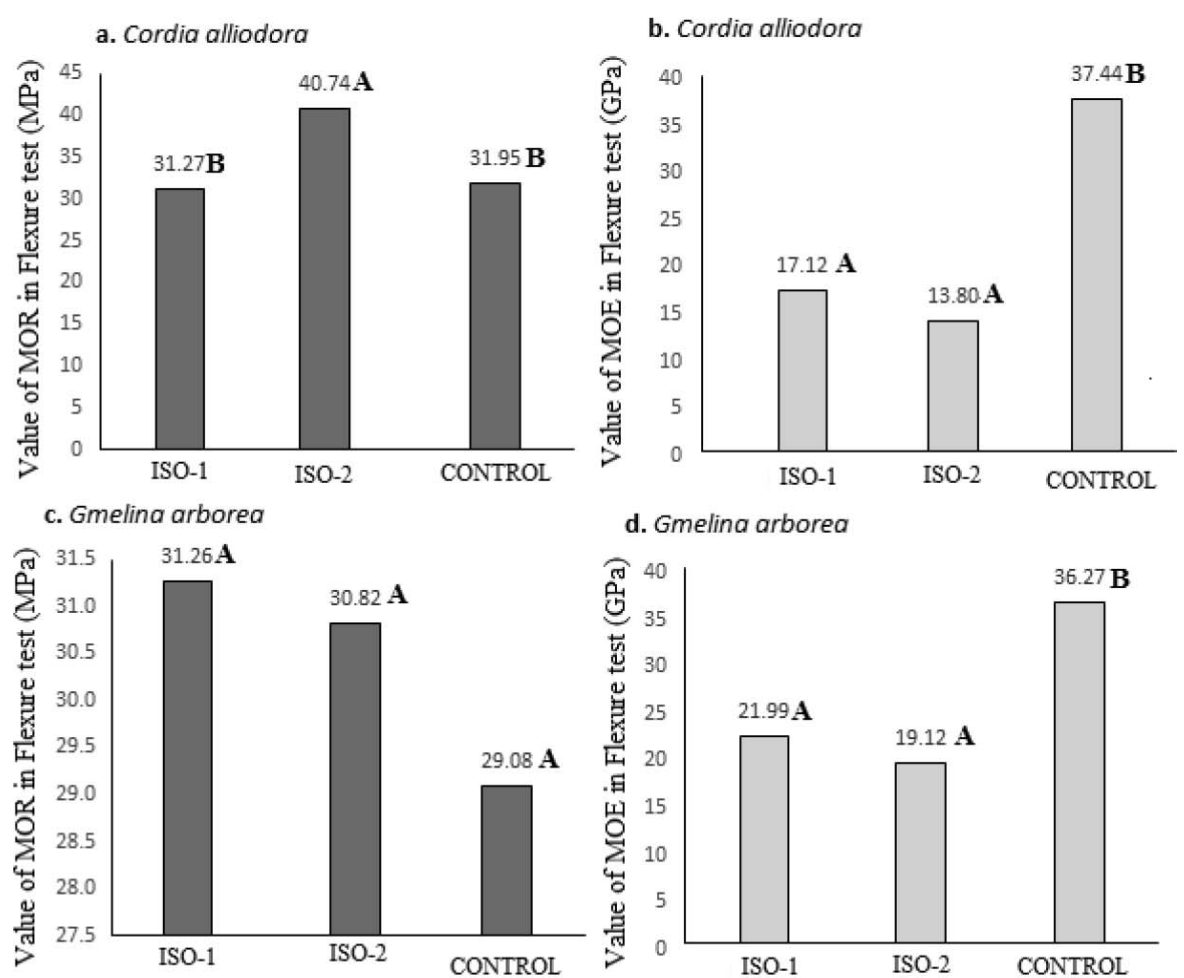

d. Gmelina arborea
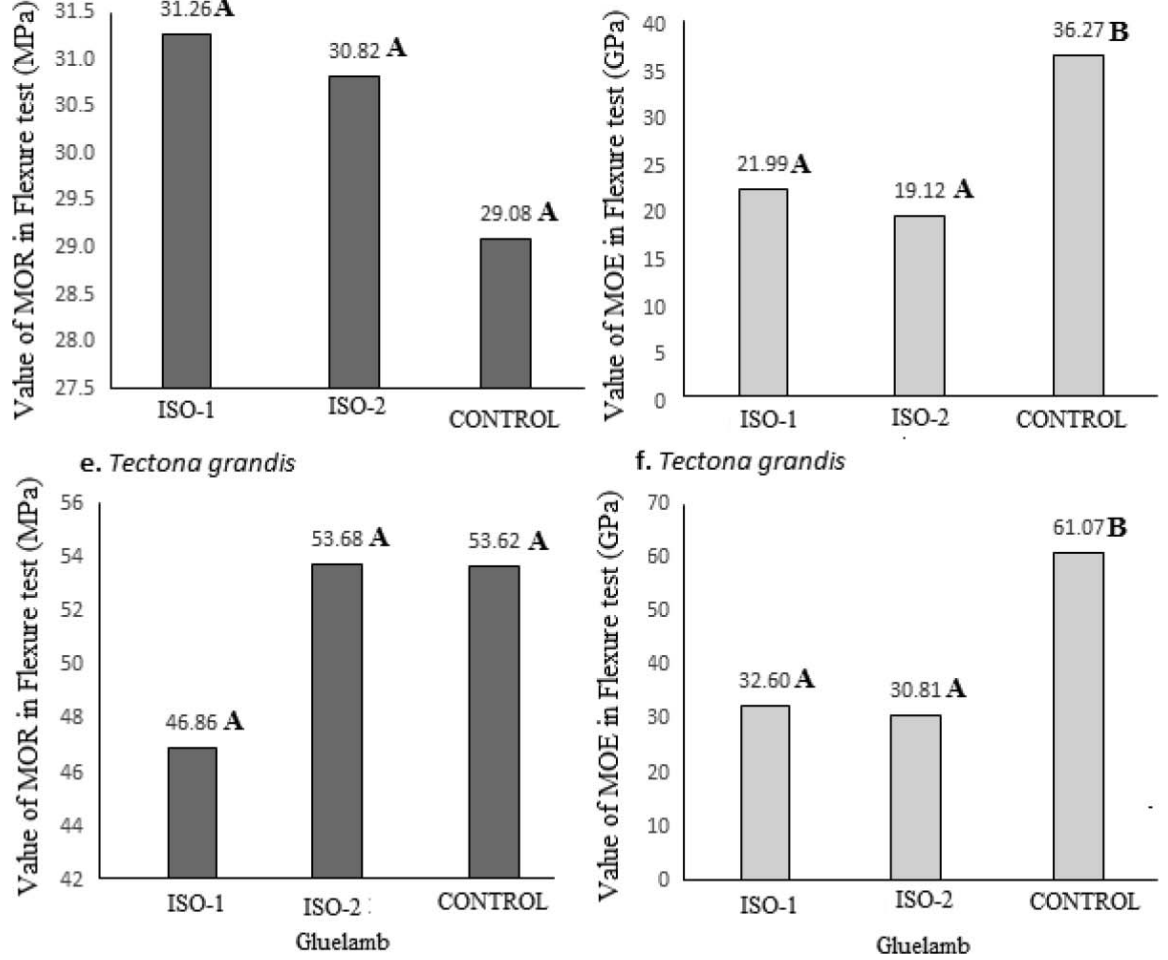

Figure 2.-Modulus of rupture (MOR; $a, c, e)$ and modulus of elasticity (MOE; $b, d, f)$ in the flexural test of the beams of Cordia alliodora, Gmelina arborea, and Tectona grandis. Different letters indicate that the values are statistically different at a confidence level of 95 percent for the same defects.

In $T$. grandis, all the shear stress values were statistically different. The highest shear stress was obtained in the control beams, followed by the ISO-2 and then by the ISO-1 beams (Fig. 3e). The failure percentage in this species was lower than 7 percent for the ISO beams; however, the percentage for ISO-1 beams was higher than that for ISO-2 (Fig. 3f).

In relation to the delamination or rupture percentage at the glue line for both adhesives, no significant difference was found between both adhesives for the three species examined (Table 3). In general, the application of the adhesive had little effect on the shear stress and delamination percentage in the glue line between the ISO beams of $C$. alliodora and $G$. arborea and the control beams. This is because the beams of these species that used the two types of adhesive showed shear stress values similar to those of the control beams (Fig. 3; Table 3). However, the glue lines in $G$. arborea and in T. grandis presented low failure percentages (less than 10\%) in the different beams studied. The results obtained for $C$. alliodora and $G$. arborea
Table 3.-Values of moisture content in wet condition and failure in glue line for previously inside-out (ISO; moving the pith out) tested beams of Gmelina arborea, Tectona grandis, and Cordia alliodora. $^{2}$

\begin{tabular}{cccc}
\hline \hline Species & Beam type $^{\mathrm{b}}$ & $\begin{array}{c}\text { Moisture } \\
\text { content (\%) }\end{array}$ & $\begin{array}{c}\text { Failure in } \\
\text { glue line (\%) }\end{array}$ \\
\hline Gmelina arborea & ISO-1 & $99.44 \mathrm{~A}$ & $0.05 \mathrm{~A}$ \\
& ISO-2 & $103.89 \mathrm{~A}$ & $0.60 \mathrm{~A}$ \\
& Control & $97.84 \mathrm{~A}$ & - \\
Tectona grandis & ISO-1 & $35.11 \mathrm{~A}$ & $7.55 \mathrm{~A}$ \\
& ISO-2 & $36.61 \mathrm{~A}$ & $1.56 \mathrm{~A}$ \\
& Control & $37.53 \mathrm{~A}$ & - \\
& ISO-1 & $46.31 \mathrm{~A}$ & $0.05 \mathrm{~A}$ \\
& ISO-2 & $45.59 \mathrm{~A}$ & $0.60 \mathrm{~A}$ \\
& Control & $44.12 \mathrm{~A}$ & - \\
\hline \hline
\end{tabular}

\footnotetext{
${ }^{a}$ Different letters indicate that the values are statistically different at a confidence level of 95 percent for the same defects.

${ }^{b}$ The ISO-1 treatment used Resistol 5003 and the ISO-2 treatment Reactive 8000 to glue the two pieces.
} 
a. Cordia alliodora

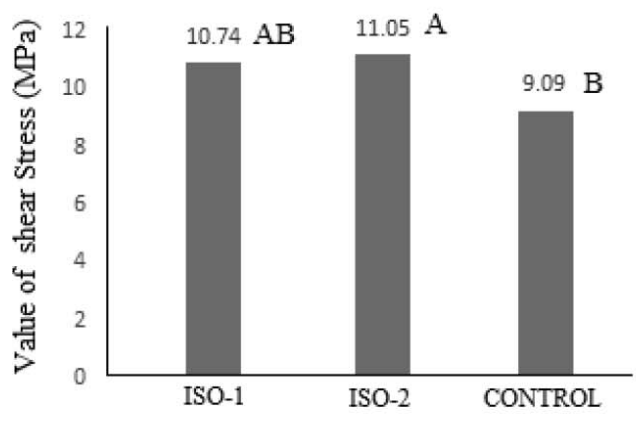

c. Gmelina arborea

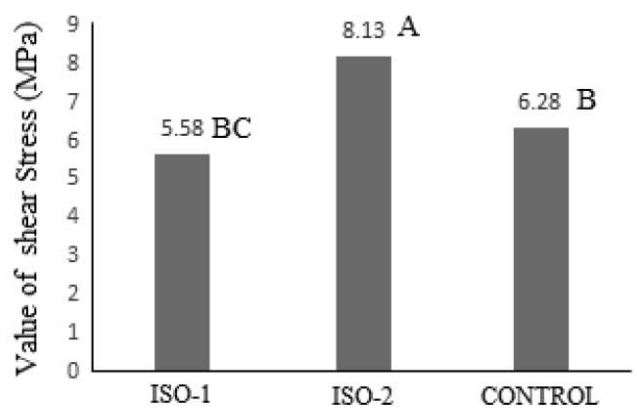

e. Tectona grandis

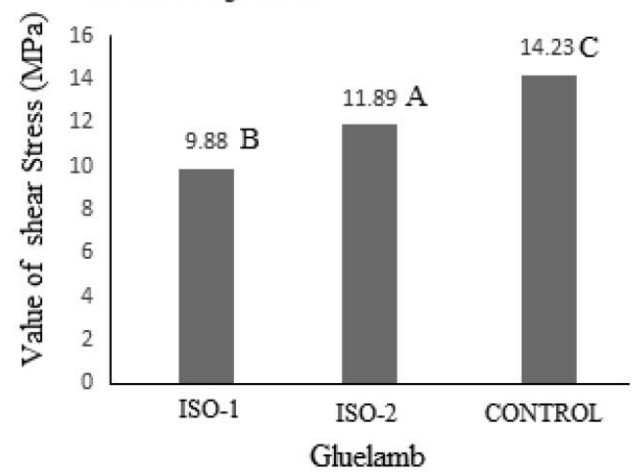

b. Cordia alliodora

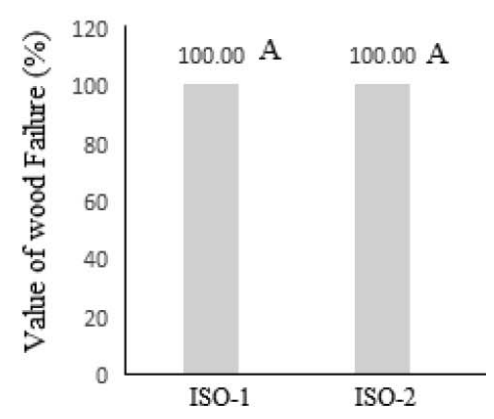

d. Gmelina arborea

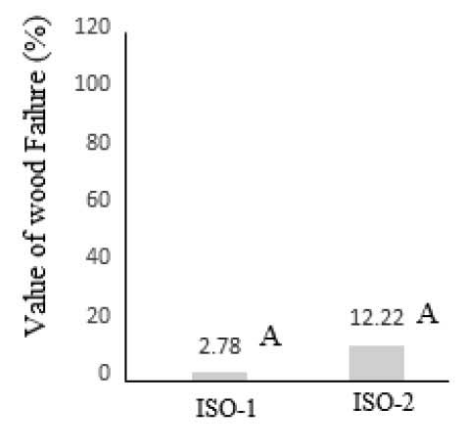

f. Tectona grandis

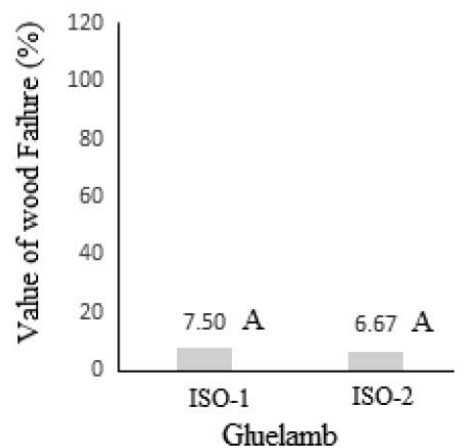

Figure 3.-Values of shear stress $(a, c, e)$ and wood failure $(b, d, f)$ determined for three species glued as part of an inside-out (moving the pith out) test. Different letters indicate that the values are statistically different at a confidence level of 95 percent for the same defects.

confirm that the pith separation and the new conformation of the beams from using adhesives do not affect the shear stress.

In the case of $T$. grandis, shear values were lower than those of solid wood (Fig. 3). The low resistance in this property can be attributed to the nature of the species. Teakwood possesses a high content and variety of extractives (Moya et al. 2014). These extractives sometimes can have negative effects on the wettability of the surface, which leads to reduced adhesion properties (Gossenreiter et al. 2013, Moya et al. 2014). Although the pith separation in $T$. grandis can reduce the presence of defects, an adhesive or treatment that helps improve adhesion at the glue line should be procured in the future. Additionally, the low moisture content can be contributing to the low adhesion in T. grandis (Table 3). Teak showed a moisture content close to 30 percent, which may not be adequate for the use of these adhesives because they are intended for wood with a higher moisture content.

\section{Conclusions}

The results showed that ISO beams can be produced with lumber from small-diameter logs that come from fastgrowing plantations of $T$. grandis, $G$. arborea, and $C$. alliodora in tropical climates. These beams can be built after separating the pith and gluing while in the green condition. These beams had reduced warp and checks. The MOR in the flexural test of the glued beams was not different from that of solid (control) wood beams. However, the beams obtained with this ISO process lose rigidity; the MOE in the flexural test was reduced in the three studied species. In the case of glue line shear stress, the behavior of $G$. arborea and $C$. alliodora beams was similar to that of solid wood (control) beams. In $T$. grandis beams the shear stress appeared to be reduced due to adhesion problems. For this species, greater care is needed in the gluing process for beam construction. 


\section{Acknowledgments}

The authors thank Vicerrectoría de Investigación y Extensión from Instituto Tecnológico de Costa Rica. The authors also thank BARCA (Brinkman y Asociados Reforestadores de Centro América S. A.) and Corporación Buen Precio for supplying the wood samples for this study.

\section{Literature Cited}

ASTM International. 2013a. Standard test methods of static tests of lumber in structural sizes. ASTM D198. In: Annual Book of ASTM Standards. Volume 04.10. ASTM International, West Conshohocken, Pennsylvania.

ASTM International. 2013b. Test methods for small clear specimens of timber. ASTM D143-08. In: Annual Book of ASTM Standards. Volume 04.10. ASTM International, West Conshohocken, Pennsylvania.

ASTM International. 2013c. Standard test method for strength properties of adhesive bonds in shear by compression loading. ASTM D905-08. In: Annual Book of ASTM Standards. Volume 15.06. ASTM International, West Conshohocken, Pennsylvania.

ASTM International. 2013d. Standard test methods for integrity of adhesive joints in structural laminated wood products for exterior use. ASTM D1101I-97a. In: Annual Book of ASTM Standards. Volume 15.06. ASTM International, West Conshohocken, Pennsylvania.

Darmawan, W., D. Nandika, I. Rahayu, M. Fournier, and R. Marchal. 2013. Determination of juvenile and mature transition ring for fast growing sengon and jabon wood. J. Indian Acad. Wood Sci. 10(1):3947.

Espinoza, J. and R. Moya. 2013. Logging and industrialization of two Gmelina arborea plantations with different degrees of slopes. Rev. Chapingo Ser. Cienc. Forestales Ambiente 19(2):237-248.

Forest Products Laboratory. 1987. Wood Handbook: Wood as an Engineering Material. USDA Agricultural Handbook 72. USDA Forest Products Laboratory, Madison, Wisconsin. 342 pp.

Gossenreiter, W., A. Teischinger, C. Buksnowitz, and C. Hansmann 2013. Bonding properties of teakwood (Tectona grandis $L f$ ) with PUR and MUF in dependence on surface treatment time. Wood Res. 58(1):01-10

Hamner, P., M. S. White, and P. A. Araman. 2006. The effect of curve sawing two-sided cants from small diameter hardwood sawlogs on lumber and pallet part yields. Forest Prod. J. 56(10):80-85.

Maeglin, R. and R. Boone. 1988. Saw-dry-rip improves quality of random length yellow-poplar 2 by 4's. FPL-RP-490. USDA Forest Products Laboratory, Madison, Wisconsin. 15 pp.

Moya, R., B. Bond, and H. Quesada. 2014. A review of heartwood properties of Tectona grandis trees from fast-growing plantations. Wood Sci. Technol. 48(2):411-433.

Moya, R. and M. Tomazello. 2009. Radial variation of the wood anatomical structure of Gmelina arborea trees from different climatic and management conditions in Costa Rica. Sci. Florestalis 37(83):105-177. (In Portuguese.)

Moya, R., E. Ureña, C. Salas, F. Muñoz, and O. Espinosa. 2013. Kiln drying behavior of lumber from 10 fast-growing plantation species in Costa Rica. Wood Mater. Sci. Eng. 8(1):37-45.

Muñoz, F. and R. Moya. 2008. Moisture content variability in kiln-dried Gmelina arborea: Effect of radial position and anatomical features. $J$. Wood Sci. 54(4):318-322.

Patterson, D., R. Kluender, and J. Granskog. 2002. Economic feasibility of producing inside-out beams from small-diameter logs. Forest Prod. J. 52(1):23-26.

Patterson, D. and X. Xie. 1998. Inside-out beams from small-diameter Appalachian hardwood logs. Forest Prod. J. 48(1):76-80.

Ratnasingam, J., A. M. Abdullah, G. Ramasamy, and C. Seng. 2013. Processing small-diameter logs. J. Appl. Sci. 13(3):341-347.

Salas, C. and R. Moya. 2014. Kiln, solar and air-drying behaviour of lumber of Tectona grandis and Gmelina arborea from fast-grown plantations: moisture content, wood color and drying defects. Drying Technol. 32(3):301-310.

Scholl, M., J. Wiedenbeck, P. Blankenhorn, C. Ray, L. Stover, and B. Beakler. 2008. A comparison of kiln-drying schedules and quality outcomes for 4/4-thickness black cherry lumber sawn from smalldiameter logs. Forest Prod. J. 58(12):41-48.

Serrano, J. and D. Cassens. 2001. Reducing warp and checking in plantation grown yellow poplar 4 by 4 's by reversing part positions and gluing in the green condition. Forest Prod. J. 51(11/12):37-40.

Serrano, R. and R. Moya. 2011. Timber processing, uses and marketing of wood in Costa Rica: Historical aspects and analysis. Rev. Forestal Mesoam. 9(21):1-12. (In Spanish.)

Sidney, R., J. Charles, P. Kozlik, J. Bois, and E. Wengert. 1988. Dry kiln schedules for commercial woods: Temperate and tropical. GTR-57. USDA Forest Products Laboratory, Madison, Wisconsin. 58 pp. 